\title{
Influence of the structure of educational and professional motivation on the level of aspirations of psychology students of higher educational institutions
}

\author{
Victoria Dmitrieva ${ }^{1, *}$, Vladimir Morozov ${ }^{1}$, Anzhela Romanova ${ }^{1}$, Elena Afanasenkova ${ }^{2}$, \\ Natalia Pankstyanova ${ }^{2}$ \\ ${ }^{1}$ Russian State Social University, Wilhelm Pieck street, 4, build.1, 129226, Moscow, Russia \\ ${ }^{2}$ Sakhalin state University, Lenin street, 290, build. 6, 693008, Yuzhno-Sakhalinsk, Russia
}

\begin{abstract}
Substantiation of the research objectives: The current situation on the labor market imposes new requirements on university graduates, who at the time of graduation from higher educational institutions must have competencies that ensure their competitiveness. Some inconsistency between professional and educational standards gives rise to a contradiction that modern young professionals are forced to solve when entering an independent working life. These risks can be significantly reduced if, during the period of study, students form a harmonious hierarchy of motives in the structure of professional motivation, a realistic level of aspirations and a professionally determined life position. All this determines the purpose of the study: to reveal the features of the hierarchy of motives in the structure of educational and professional motivation of graduatespsychologists of higher educational institutions and the level of their aspirations for future activities. Research methods: method of theoretical analysis and systematization of scientific ideas; ascertaining experiment; methodology for determining the level of personality aspirations (V.K. Gerbachevsky); method of mathematical statistics - Student's t-test. Research results. The study made it possible to establish that the group of leading and accompanying motives of educational and professional activity of psychology students includes: a cognitive motive, a motive for the regularity of the intended results, a motive for self-esteem of personal potential, a motive for self-mobilization. The average level of formation of personality aspirations in future activities was revealed. A correlation relationship has been established between the level of students' aspirations and the leading motives: the cognitive motive and the motive of the regularity of the intended results. Key findings and their significance. In the course of the study, the features in the structure of the hierarchy of educational and professional motivation of psychology students were revealed, the level of their aspirations was determined. This is consistent with the specifics of psychological and pedagogical activity, since it reflects the personal meaning and determines the life-meaning orientations of this activity for future psychologists in the field of education. The data of the conducted study can be useful in the implementation of effective
\end{abstract}

\footnotetext{
* Corresponding author: dmitrievava@rgsu.net
} 
psychological and pedagogical support of students receiving a profession of a humanistic orientation.

\section{Introduction}

The requirements of the modern labor market are such that the traditional system of training specialists in higher educational institutions does not fully satisfy their expectations and needs. That is why the education system of the Russian Federation is undergoing serious changes and is in the regime of active reform. Nowadays, a specialist, on the one hand, must fully meet the expectations of the employer (otherwise he will not withstand the competition even at the time of hiring). On the other hand, at the stage of professional training, while still a student, he must comply with the federal state educational standard of his field of study in matters of mastering his future profession, which are still lagging behind and do not fully reflect professional standards. In addition, there is an acute issue of professional retraining or advanced training of already working and accomplished specialists, all for the same reason - cardinal changes in the modern labor market.

All these are modern challenges that determine professional requirements (guidelines) that a specialist must meet today: a high level of professional competence, professional responsibility, a high learning threshold, great mobility, communicative competence, polymotivation in activities, a high level of professional aspirations, stable socially adaptive meaningful guidelines, the ability to be creative (thinking outside the box, making unusual decisions), focus on self-development (personal, professional) and productive self-realization in the profession. That is why the issues of training (retraining, advanced training) of specialists for professional activity in modern conditions is a rather urgent research problem. So, N. V. Drozdova notes that "Questions of the student's personal development and the formation of his readiness for future professional activity are key in the theory and practice of improving the work of a modern higher educational institution". Moreover, it is during the period of study at the university when "the process of personality formation in professional activity, the development of its professional abilities and self-improvement occurs, the life position of a person is determined, an attitude to both educational and professional activities is formed" [1].

The main driver of the professional formation and development of a future specialist is the motivation of educational and professional activities, subsequently labor activity. Motivation, in turn, influences the level of the personality's aspirations in activity and is always closely connected with the system of its values, life-meaning guidelines, what ultimately determines the level of its self-realization in the profession.

In modern psychology, issues of motivation, including educational and professional one, were developed by L.P. Stankevich, I.P. Polyakova [2]; R.I. Tsvetkova [3]; S. A. Sharovatova [4]; T. O. Gordeeva [5]; O. A. Sychev [6]; E. L. Afanasenkova [7]; M. V. Azhiev [8] and others; the problematics of the aspirations of the individual in the activity were considered by A. V. Shumikhina [9]; K.R. Sidorov [10]; S. T. Dzhaneryan, A. E. Kim [11] and others; A. N. Mikhailyuk [12], Ya. V. Sayko, N.I. Guslyakova [13]; N. V. Drozdova [14]; E. Yu. Zarubko [15]; V.P. Musin [16] and others studied the specifics of the formation of lifemeaning orientations, in particular, the life position during the period of vocational training; various problems of professional self-realization, including at the stage of educational and professional training, were studied by P. Miquelon, R. J. Vallerand [17]; A. A. Vasilyuta [18]; L. V. Manzhos and others [19]; T.Z. Kozlova [20]; Nataliya N. Vasyagina et al. [21]; Vereitinova, T., \& Dmitrieva, V. [22]; Kislyakov P.A. and others [23]; Morozov V.A. and others [24]; Meneghetti A. [26]. 
Based on the analysis of scientific approaches to understanding the nature of motive and motivation and our research interest, educational and professional motivation will be understood as "a special type of motivation characterized by a complex structure that has a connection with the level of intellectual development of the individual and the nature of scientific activity, largely determining the level of student success in educational and professional activities and their general professional orientation" [25]. At the same time, it is important to understand that the area of activity is determined precisely by the leading and accompanying motives in the structure of motivation, which are in a certain hierarchical relationship among themselves.

The content of these motives determines the content of the activity itself, and motivation as a whole also reflects the system of values (meanings) of the individual. That is, it is closely related to the life-meaning orientations of the individual and the level of its aspirations. So, Ya.V. Sayko and N.I. Guslyakova, relying on the research of K.A. Abulkhanova-Slavskaya, G.A. Vaizer, V.N. Kvin, D. A. Leontyev, V. E. Chudnovsky, consider life-meaning orientations as an integral system of "conscious and selective connections, reflecting the orientation of the individual, the presence of life goals, meaningfulness of choices and assessments, satisfaction with life (self-realization) and the ability to take responsibility for it, influencing its course" [13]. For our study, it is important to clarify that the content of the concept of life-meaning orientations can be revealed through the following categories: "life position", "life line", "life strategy", "life perspective". Among these concepts, the most interesting for us is the definition of a life position, since it reflects life relationships, the way of their implementation, which meets - does not meet the needs, values, and capabilities of the individual. This is the choice that a person makes under specific conditions, this is the way of his social life, the place in the system of professional relations (of a particular profession), the way of self-expression and self-realization in activities, including educational and professional ones. In this case, the criterion of success - failure of a person in activity will be the level of his aspirations.

K.R. Sidorov, relying on the study of K. Levin, H. Heckhausen, V.N. Myasishv, B.G. Ananyev, B.V. Zeigarnik, V.K. Gerbachevsky, defines the level of personality aspirations as striving to achieve a goal of that degree of complexity for which a person considers himself capable, while achieving this goal not only brings personal satisfaction to a person, but stimulates him to achieve new, more difficult goals [10].

In a situation of professional training of future specialists, the level of personality aspirations is directly related to educational and professional activities, i.e. "those specific conditions in which the professionalism of the future specialist develops" [25]. As R.I. Tsvetkova notes, "The level of a student's motivational sphere depends on the methods, conditions and means of university education, awareness of their own meaning of learning, subject-reflective attitude to teaching subjective activity and subjective attitude" to it $[3, \mathrm{p}$. 79]. That is, it is during this period that not only the professional formation of the personality takes place, but also the formation of a system of motives in the structure of educational and professional motivation, which is subsequently transformed into labor. At the same time, motivation always influences the level of aspirations in actual activity for the individual and reflects his life-meaning orientations. Therefore, in our study, we decided to establish the relationship between the motivation of the educational and professional activity of university students (its structure) and the level of their aspirations as a phenomenon of a person's selfesteem for their own achievements of more difficult goals.

Thus, the conducted theoretical analysis on the problematic under consideration determined the goal of our study: to diagnose the features of educational and professional motivation of university psychologists-graduates, i.e. to determine the leading and accompanying motives in the hierarchy of the structure of motivation of actual activity, and 
also to establish the level of their aspirations in future activities through the identified components of the motivational structure of the personality.

\section{Materials and methods}

To achieve the goal of the study, within the framework of the ascertaining experiment, we used the test of V.K. Gerbachevsky to determine the level of personality aspirations. This diagnostic tool allows determining not only the level of personality aspirations, but also those components in the structure of motivation that determine it, and also makes it possible to establish the features of the hierarchy of motives in the actual activity of the individual, i.e. to identify the leading and accompanying motives.

For the diagnostic study, we chose students of the final course of the psychological and pedagogical specialization in the age range up to 25 years old, because, firstly, it is during this age period that "active personality formation, transformation of motivation, awareness of the meaning of life and its goals take place. This age is associated with the formation of an active life position, the formation of beliefs and values, the expansion of the sphere of life" $[13$, p. 210] in connection with mastering the chosen profession and entering into an independent professional activity. Secondly, "the problem of professionalism is especially relevant in the profession of a psychologist, since the psychological well-being of other people depends on the level of his qualifications" [14, p. 42], i.e. the more holistically the professional position of the future specialist is formed during training, the more chances he will have to become a highly competent specialist in psychological and pedagogical activity.

\section{Results}

In order to identify the specifics of educational and professional motivation of students of higher educational institutions, as well as to establish the relationship between the level of their aspirations for the future profession and the leading motives in motivating educational and professional activities, we conducted an ascertaining experiment. The Institute of Psychology and Pedagogy of Sakhalin State University became the base for it. The survey of respondents was conducted from February 24 to March 24, 2020. Thirty six students took part in the study. Of these, 11 fourth-year students of full-time education, specialization "Psychological and Pedagogical Education", profile "Psychology of Education", and 25 fourth-year students of correspondence courses, the same specialization. The age of the respondents varies from 20 to 25 years.

The toolkit of our study was the methodology for assessing the level of aspirations by V.K. Gerbachevsky. Based on the test results, the structure of a person's motivation in actual activity and the level of his aspirations are determined. The structure includes 15 scales. According to the methodology, all scales (as components of the motivational structure) are divided into four groups. The first group: the components that represent the core of the motivational structure of the personality (the hierarchy of motives in the motivational core). The second group: the components associated with the achievement of rather difficult goals, as well as the level of real aspirations and capabilities of the optant. The third group: the components that make up the predictive estimates of the subject's activities (the potential capabilities of the optant). The fourth group: components reflecting the causal factors of activity (assessment of one's own capabilities; the degree of formation of one's own initiative). In the process of summing up the results of testing, according to this methodology, an additional fifth component is highlighted: the level of the optant's aspirations, determined through the degree of formation of the self-esteem motive. The final values according to the 
level of the individual's aspirations in the future profession are distributed according to the degree of its formation: low, medium, high.

We placed the results of calculating the values for all groups of educational and professional motivation and the value of the fifth component in the histogram (Fig. 1).

\section{The level of formation of motivation in educational and professional activities}

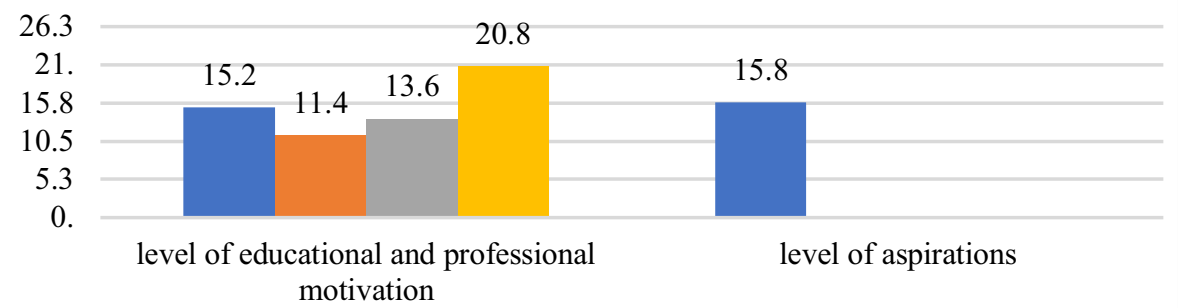
- Motivational core
- Level of real opportunities
- Potential opportunities
Assessment of one's own capabilities

Fig. 1. Indicators of the formation of motivation in educational and professional activities of students and the level of their aspirations in the future profession.

A comparative analysis of the obtained results shows that the level of formation of all motives, except for the motives reflecting the causal factors of activity (group 4), in the hierarchy of educational and professional motivation for all groups, as well as the level of aspirations, have average values. The motives of the fourth group have the highest degree of expression.

Consider the distribution of these values as a percentage. In the first group (motivational core), a high level was shown by $22 \%$ of respondents ( 8 students), an average $-72 \%$ ( 26 students), a low level - 6\% (2 students). The second group (level of real opportunities): a high indicator for $31 \%$ of optants (11 students), an average - 44\% (16 students), a low - $25 \%$ (9 students). In the third group (potential opportunities), a high level was recorded in $31 \%$ of the surveyed (11 students), an average - 56\% (20 students), a low - 13\% (5 students). The fourth group (assessment of one's own capabilities, i.e. causal factors of activity) - a high result $-87 \%$ of respondents (31 students), an average - 13\% (5 students), a low value was not recorded.

As a percentage, the value of the level of aspiration was distributed as follows: $41 \%$ of the tested (15 students) have a high level of aspirations, 53\% (19 students) have an average level, and 6\% ( 2 students) have a low level. Analysis of the percentage of the results obtained allows making the assumption that the level of aspiration can be interconnected with the level of the fourth group of motives (causal factors of activity), for this, using the method of mathematical statistics - the Student's t-test, we will clarify whether there is a correlation between them. The obtained empirical value $t$ (4.6) is in the zone of significance.

Comparing the percentage of components in the structure of motivation for educational and professional activities, we came to the conclusion that it is necessary to single out the leading motives in each group to determine the features of the structure of educational and professional motivation of university psychologists-graduates. The results are recorded in a histogram (Fig. 2). 
Leading motives in the structure of motivation for educational and professional activities

IV group. Assessment of one's own capabilities

$\square$ M. of the regularity of intended results

M. of self-assessment of personal potential

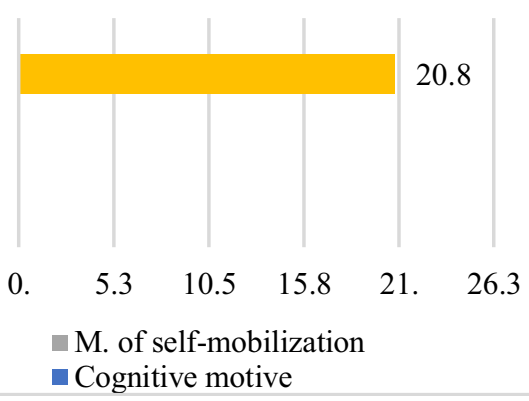

Fig. 2. Histogram of the leading motives of each motivation group for EPA.

According to the results of the comparative analysis, the data were distributed as follows:

Group 1. Leading motive: cognitive. A high level of formation among $61 \%$ of respondents (22 students), an average - 39\% (14 students), low - not established. Associated motive: selfesteem motive. A high level of maturity among $53 \%$ of respondents (19 students), average $42 \%$ (15 students), low - 5\% (3 students).

Group 2. Leading motive: the motive of self-assessment of personal potential. A high level of education was found in $64 \%$ of optants ( 23 students), average - $36 \%$ (13 students), low - not found.

Group 3. Leading motive: the motive of self-mobilization. A high level - in $44 \%$ of the surveyed (16 students), average - 39\% (14 students), low - 17\% (8 students).

Group 4. Leading motive: the motive of the regularity of the intended results. A high level is among $72 \%$ of respondents (26 students), average - $28 \%$ (10 students), low - not identified.

Using the Student's t-test, we compare the values of the self-esteem motive and the cognitive motive in order to determine whether there is a direct relationship between them. The obtained empirical value $t$ (7.6) is in the zone of significance, therefore, we can talk about the existing dependence of the degree of manifestation of the self-esteem motive on the value of the cognitive motive. That is, the higher the level of formation of the cognitive motive, the higher the level of the self-esteem motive of students towards themselves for the ability to set more and more complex goals in educational and professional activities for mastering the future profession through its knowledge.

\section{Discussion}

Thus, the structure of educational and professional motivation of university psychologistsgraduates has the following features in its hierarchy. Firstly, in the general group "Motivation of achievement", the cognitive motive and the motive of the regularity of the intended results have the greatest degree of expression, i.e. act as a leading and accompanying motive in this type of motivation for educational and professional activities. This indicates the presence of a high personal interest of the respondents in the results of their activities.

Secondly, both of these motives are correlated with the motive of self-esteem, which once again confirms the presence of a deep personal meaning for university students in the process of mastering a future profession - a psychologist in the educational sphere, and their personal interest in finding their place in the system of professional relations. This conclusion is consistent with the study of L. P. Stankevich, I. P. Polyakova, who note that "the content of 
the process of motivation, the nature and characteristics of motives are interconnected with the help of a certain system of values. Values permeate the process of motivation at all stages, from the moment of emergence to the final decision on the readiness or refusal to take any action aimed at satisfying an urgent need. Such values affect all motivational formations (attitudes, interests, habits, attitudes), influencing their formation, filling their content with a unique personal meaning", life-meaning orientations [2, p. 134].

Thirdly, in the general group "Relationship motivation", the motive of self-assessment of personal potential and the motive of self-mobilization have the highest values in terms of their severity, i.e. act as a leading and accompanying motive in this type of motivation for educational and professional activities. This indicates that optants are capable and ready to satisfy their need for professional development through educational and professional activities. At the same time, the personal, semantic and emotional attitude to this activity is deeply conscious and positive. Since, while studying at a university in the chosen area, students, on the one hand, understand that the chosen profession will allow them to reveal their personal potential through activity, multiply their internal capabilities, first of all, the ability for professional growth and development. On the other hand, they are ready to show will activity in educational and professional activities in situations of difficulties that require special efforts to overcome them, the state of internal involvement: motivational-personal, professional-intellectual, psychophysiological qualities and opportunities in the process of mastering the chosen profession.

Fourth, graduates-psychologists as a whole have a sufficiently formed level of personality aspirations in their future profession. Which is mediated primarily by the motive of the regularity of the intended results (group 4), reflecting the causal factors of activity, i.e. assessment of their own capabilities by the respondents, both in current and future professional activities. In addition, the identified level of aspirations is caused by a cognitive motive (group 1), which characterizes the subject as a person showing interest in actively learning the content and essence of the future profession for effective self-realization in it in the future. The revealed relationship between the level of aspirations and the motives that determine it indicates the presence of a meaning-forming component in the structure of motivation of future educational psychologists for whom the cognitive component in future activities is important, the factor of their own activity and initiative in professional selfdevelopment. This testifies to their focus on solving more and more difficult professional tasks in future activities related to helping people - a humanistic component in the structure of their life position.

\section{Conclusions}

Thus, as a result of the study, our goal was achieved. And this allowed us to come to the following conclusions.

The hierarchy of educational and professional motivation of university psychologistsgraduates has the following features. In the achievement motivation group, the leading motive is the cognitive motive, and the accompanying one is the motive of the regularity of the intended results. In the relationship motivation group, the leader is the motive of selfassessment of personal potential, and the accompanying motive is the motive of selfmobilization. This hierarchy is consistent with the content and the very essence of psychological and pedagogical activity and reflects the personal meaning of this activity for the future specialist, which determines his life-meaning orientations.

For the group of surveyed respondents, a sufficient level of formation of personality aspirations in the future profession was established. It is determined by such leading motives as the cognitive motive and the motive of the regularity of the intended results. This indicates, first of all, that for future psychologists, not only the process of activity, the significance of 
the results to which it leads, but also the effectiveness of self-realization in the future profession is of great importance.

\section{References}

1. N.V. Drozdova, Psychology and pedagogues: methodology and problems of practical application 51, 40-44 (2016) DOI: https://doi.org/10.24412/Fg4_c4UeNbM

2. L.P. Stankevich, I.P. Polyakova, Philosophy and Society 2, 126-135 (2004) https://doi.org/10.24412/Fg56VHRQ_uU

3. R.I. Tsvetkova, Psychological science and education 11(4), 76-80 (2006) DOI: https://doi.org/10.17759/pse https://psyjournals.ru/psyedu/2006/n4/Tsvetkova.shtml

4. S.A. Sharovatova, Notes of the Komsomolsk-on-Amur State Technical University 2(4), 47-52 (2010) DOI: https://doi.org/10.17084/2010.iv-2(4).8

5. T.O. Gordeeva, Siberian Psychological Journal 62, 38-53 (2016) DOI: https://doi.org/10.17223/17267080/62/4

6. T.O. Gordeeva, O.A. Sychev, Vestnik of Moscow University. - Series 14. Psychology 1 (2017) DOI: https://doi.org/10.11621/vsp.2017.01.69

7. E.L. Afanasenkova, Pedagogical education in Russia 10, 72-80 (2017) DOI: https://doi.org/10.26170/po17-10-11

8. M.V. Azhiev, MNKO 4(71), 317-319 (2018) DOI: https://doi.org/10.24412/Fg6A0e6wPOU

9. A.V. Shumikhina, Russian psychological journal 5(4), 90-92 (2008) DOI: https://doi.org/10.24412/Fg6Ijm7IsjU

10. K.R. Sidorov, Vestnik of the Udmurt University. Series "Philosophy. Psychology. Pedagogy" 2, 40-41 (2014) DOI: https://doi.org/10.24412/Fg5AZCHzh0Y

11. S.T. Dzhaneryan, A.E. Kim, Psychology and Psychotechnics 3, 1-12 (2018) DOI: https://doi.org/10.7256/2454-0722.2018.3.26311

12. A.N. Mikhailyuk, Russian psychological journal 8(3), 74-80 (2011) DOI: https://doi.org/10.21702/rpj.2011.3.8

13. Ya.V. Sayko, N.I. Guslyakova, Vestnik of the South Ural State Pedagogical University 10, 209 (2013) DOI: https://doi.org/10.24412/Fg5AG3mu9Ng

14. N.V. Drozdova, Psychology and pedagogy: methodology and problems of practical application 51, 40-44 (2016) DOI: https://doi.org/10.24412/Fg4_c4UeNbM

15. E.Yu. Zarubko, Internet journal "World of Science". Pedagogy and psychology 4(6) (2018) DOI: https://doi.org/10.24412/Fg6KWdIVNg4

16. V.P. Musina, Alma mater. Higher School Herald 7, 49-53 (2019) DOI: https://doi.org/10.20339/AM.07-19.049

17. P. Miquelon, R.J. Vallerand Motiv Emot. 30(4), 259-272 (2006) https://doi.org/10.1007/s11031-006-9043-8

18. A.A. Vasilyuta, Research and development. Social and humanitarian research and technology 3(2), 67-69 (2014) DOI: https://doi.org/10.12737/4664

19. L.V. Manzhos, S.A. Khazova, F.R. Hatit, Vestnik of the Adyghe State University. Series 3: Pedagogy and Psychology 3(162), 83-89 (2015) DOI: https://doi.org/10.24412/Fg6VtMt_u_k

20. T.Z. Kozlova, Knowledge. Understanding. Skill 3, 63-69 (2017) DOI: https://doi.org/10.17805/zpu.2017.3.5 
21. N.N. Vasyagina, E.L. Afanasenkova, J.A. Vedyashkina, S.A. Vasyagina, N.V. Abramovskih, The European Proceedings of Social \& Behavioural Sciences EpSBS (Web of Science) LXIV, $740 \quad-747 \quad$ (2019) ISSN: 2357-1330 http://dx.doi.org/10.15405/epsbs(2357-1330).2019.7.1

22. T. Vereitinova, V. Dmitrieva, International Journal of Psychology 51, S1 (2016) DOI: https://doi.org/10.1002/ijop.12313

23. P.A. Kislyakov, A.A. Sarkisyants, A.I. Rybakova, V.N. Feofanov, N.V. Belyakova, A.V. Romanova, PONTE International Scientific Researchs Journal 73(12) (2017) DOI: http://dx.doi.org/10.21506/j.ponte.2017.12.16

24. V.A. Ilyin, T.I. Bonkalo, E.A. Petrova, V.A. Morozov, O.I. Mironova, Mediterranean Journal of Social Sciences (2015) http://dx.doi.org/10.5901/mjss.2015.v6n4s2p236

25. E.L. Afanasenkova, Pedagogical education in Russia 10, 72-80 (2017) DOI: https://doi.org/10.26170/po17-10-11

26. A. Meneghetti, EPJ Web of Conferences. EDP Sciences 224, 06003 (2019) https://doi.org/10.1051/epjconf/201922406003 